\title{
Acid phosphatase polymorphism within and among populations of Cauliflower (Brassica oleracea var botrytis)
}

\author{
Celso Luis Marino ${ }^{1}$, Marcos Aparecido Gimenes ${ }^{1}$, Norberto da Silva ${ }^{2}$ and Catalina Romero Lopes ${ }^{1}$ \\ ${ }^{1}$ Departamento de Genética, Instituto de Biociências, UNESP, Botucatu, São Paulo, Brasil. \\ ${ }^{2}$ Departamento de Agricultura e Melhoramento de Plantas, Faculdade de Ciências Agronômicas, UNESP, \\ Botucatu, São Paulo, Brasil.
}

\begin{abstract}
Eighty-one lines of cauliflower (Brassica oleracea var. botrytis) from 12 populations used to produce commercial hybrids in Brazil were screened for polymorphism in the acid phosphatase system, in order to evaluate the usefulness of this marker for the determination of the parental contamination level in hybrid seeds. Little polymorphism was detected in the examined lines, but the system appeared to be very useful for hybrid identification, since the only condition required was polymorphism between the two parental lines. If the analyzed lines were used for hybrid production, $8.4 \%$ and $12.3 \%$ of the possible crosses would result in hybrids which can be positively identified using the APS-1 and $\mathrm{B}_{1}$ loci, respectively. If only one plant of each homozygous type (SS or FF) was analyzed in each population, $41 \%$ and $50 \%$ of the possible crosses would result in hybrids which can be positively identified using the APS-1 and $\mathrm{B}_{1}$ loci, respectively.
\end{abstract}

Key words: isoenzyme, polymorphism, cauliflower.

Received: March 5, 2002; accepted: March 25, 2002.

\section{Introduction}

The use of $F_{1}$ hybrids is a very common procedure in breeding programs of Brassica species. Hybrids are grown in more than $90 \%$ of the Brazilian cauliflower fields (Ikuta, 1974; Ikuta and Paterniani, 1979). These hybrids are produced by crossing self-incompatible lines under open-field conditions. In spite of the self-incompatibility system found in the lines, a certain degree of self-crossing may happen, producing an undesirable number of non-hybrid seeds, which will determine their quality and price (Thompson, 1957; Haruta, 1962).

Isoenzymatic markers have been successfully used to identify hybrids and cultivars in many plant species (Heidrich-Sobrinho, 1982; Cardy and Kannenberg, 1982; Arús and Orton, 1983; Grossi et al., 1997). The isozyme method has proven to be one of the simplest ways to assess the level of parental contamination of seeds within a hybrid cauliflower seed lot (Nijenhius, 1977; Wills et al., 1979; Arus et al., 1985). Isoenzyme analysis is a low-cost and accessible technique (Kephart, 1990). The acid-phosphatase isoenzyme system has proven to be the most useful enzyme system for the detection of contamination within hybrid

Send correspondence to Celso Luis Marino, Depto de Genética - IB - UNESP, 18610-000 Botucatu, São Paulo, Brasil. E-mail: clmarino@ibb.unesp.br. cauliflower seeds (Nijenhius, 1971; Woods, 1976; Wills et al., 1980).

The aim of this study was to analyze acid phosphatase polymorphism in cauliflower lines used to produce hybrids in Brazil, and to evaluate the usefulness of this enzyme system to identify hybrids between different lines.

\section{Material and Methods}

\section{Plant material}

Eighty-five lines from 12 cauliflower (Brassica oleracea var. botrytis) populations cultivated in Brazil were analyzed (Table I). The number of times the lines were self-crossed is listed in Table I. Hybrids resulting from the crossing of seven Piracicaba Precoce lines and one line from the Spring Snow population were analyzed to determine the genetic control of one acid phosphatase zone.

\section{Isoenzyme analysis}

Ten-day-old cotyledons were grounded in liquid nitrogen and transferred to $1.5 \mathrm{~mL}$ tubes, to which $50 \mu \mathrm{L}$ of $0.01 \mathrm{M}$ Tris-glycine buffer, $\mathrm{pH} 8.3$, were added. The samples were centrifuged for $30 \mathrm{~min}$ at $4{ }^{\circ} \mathrm{C}$, and $20 \mu \mathrm{L}$ of the supernatants were loaded into a $10 \%$ polyacrylamide gel 
Table I - Cauliflower lines analyzed using acid phosphatase isozymes.

\begin{tabular}{lccc} 
Population & $\begin{array}{c}\text { Number of } \\
\text { progeny }\end{array}$ & $\begin{array}{c}\text { Number of } \\
\text { selfcrosses }\end{array}$ & Origin \\
\hline 1 - Wase Ataria & 7 & $\mathrm{~S}_{1}$ Sibcross & Japan \\
2 - Pa Shi Tien & 8 & $\mathrm{~S}_{3}$ Sibcross & China \\
3 - Tainung & 7 & $\mathrm{~S}_{3}$ Sibcross & Thailand \\
4 - Main Crop Benares & 8 & $\mathrm{~S}_{4}$ Sibcross & India \\
5 - PI 163485 & 7 & $\mathrm{~S}_{4}$ Sibcross & Pakistan \\
6 - PI 183214 & 2 & $\mathrm{~S}_{3}$ Sibcross & Egypt \\
7 - Kangaroo & 3 & $\mathrm{~S}_{1}$ Sibcross & Australia \\
8 - Jaragua & 7 & $\mathrm{~S}_{3}$ Sibcross & Brazil \\
9 - Piracicaba Precoce & 8 & $\mathrm{~S}_{3}$ Sibcross & Brazil \\
10 - Piracicaba Precoce $\mathrm{n} .1$ & 8 & $\mathrm{~S}_{6}$ Sibcross & Brazil \\
11 - Piracicaba Precoce 439 & 8 & $\mathrm{~S}_{5}$ Sibcross & Brazil \\
12 - Teresópolis Gigante & 8 & $\mathrm{~S}_{8}$ Sibcross & Brazil \\
\hline Total & 81 & &
\end{tabular}

prepared in $0.37 \mathrm{M}$ Tris- $\mathrm{HCl}, \mathrm{pH} 9.1$. The electrode buffer was $0.001 \mathrm{M}$ Tris-glycine, $\mathrm{pH} 8.3$. After $5 \mathrm{~h}$ of electrophoresis at $4{ }^{\circ} \mathrm{C}$, acid phosphatase activity was detected in the gels using the histochemical techniques described by Allen et al. (1963).

\section{Genetic control}

The genetic control of the APS-5 zone was based on information about the secondary structure of APS in other plants (Kephart, 1990) and on the analysis of the band patterns of a Piracicaba Precoce line, of a Spring Snow line, and of a hybrid between them, as well as of 112 plants of an F2 population.

\section{Usefulness of APS loci for hybrid identification}

The usefulness of each APS locus for hybrid identification was estimated by calculating the expected frequencies of crossing between pairs of lines, which would produce hybrids with bands acquired from both parents. The proportion of possible crossings for one locus that would result in hybrids was calculated as being:

$$
(p+q+r)^{2}=p^{2}+2 p q+2 p r+q^{2}+2 q r+r^{2},
$$

where $p=$ frequency of genotype $X X ; q=$ frequency of genotype $\mathrm{YY}$; and $\mathrm{r}=$ frequency of genotype $\mathrm{XY}$. The desirable crossing would be XX X YY, or 2pq, according to the formula above.

\section{Results and Discussion}

Three zones of enzyme activity were detected in the gels (Figure 1), as previously described and named by Arus et al. (1985). The most anodic zone was named APS-1, the

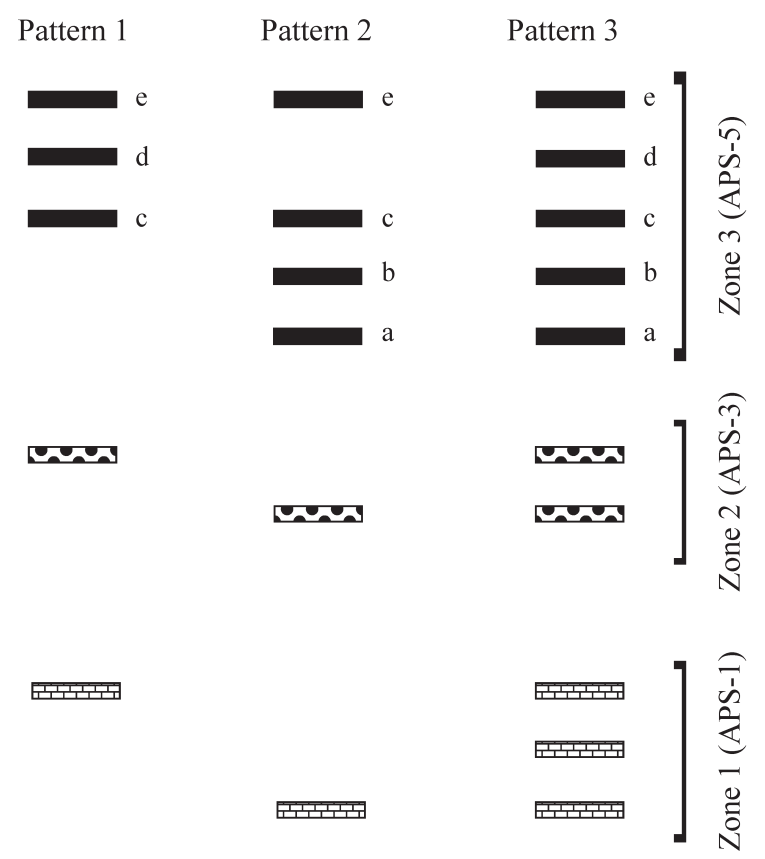

Figure 1 - Band patterns detected in each one of the three phosphatase activity zones (APS-1, APS-3 and APS-5) in cauliflower cotyledons.

intermediate zone APS-3, and the most cathodic zone APS-5 (Figure 1). Two alleles were detected in APS-1, differently from Wills and Wiseman (1980), who detected four alleles in APS-1 in an analysis of $19 \mathrm{~F}_{1}$ hybrids and inbred lines of cabbage and Brussels sprouts. Two alleles were also detected in APS-3. In the third zone (APS-5), up to five bands and three band patterns were seen (Figure 1). Pattern 1 contained three bands (e, d, and c), pattern 2 contained four bands (e, c, b, and a), and pattern 3 contained bands e, d, c, b, and a. Since the genetic control of APS-5 was not described previously, there are no reports on alleles in this zone.

The APS-5 zone was not used for hybrid identification in previous studies (Wills and Wiseman, 1980; Arus et al., 1985). The usefulness of this zone for hybrid identification was tested in this study, because of the very clear and easy to score band patterns. Crosses between plants with band patterns 1 and 2 in APS- 5 always resulted in a hybrid with pattern 3 , and an $\mathrm{F}_{2}$ population in which one-quarter had pattern 1, one-half had pattern 2 , and one-quarter had pattern 3. A chi-square test showed that there was no significant difference between the observed and the expected phenotype frequencies for a cross between two plants which are heterozygous for the same two alleles (Table II). This observation indicates that there is at least one segregating locus in this zone.

The genetic control of the APS-5 zone was proposed based on the band patterns detected in 112 plants from a cross between plants with band patterns 1 and 2 (Figure 1), and on hypothetical phenotypes of electrophoresed enzymes, as described by Kephart (1990). Pattern 1 would be 
Table II - Chi-square test of the genetic control of the segregating loci in zone APS-5.

\begin{tabular}{lcc}
\hline & \multicolumn{2}{c}{ Frequencies } \\
\cline { 2 - 3 } & Expected & Observed \\
\hline Pattern 1 & 28 & 31 \\
Pattern 2 & 28 & 27 \\
Pattern 3 & 56 & 54 \\
\hline Total & 112 & 112 \\
\hline
\end{tabular}

$\mathrm{DF}=2 ; \chi_{2}=0.4285652 ; 0.95>\chi_{2}>0.80$.

Table III - Number of heterozygous and homozygous plants for the three loci in the analyzed lines.

\begin{tabular}{lcccccc}
\hline & \multicolumn{3}{c}{ APS - 1 } & \multicolumn{3}{c}{$\mathrm{B}_{1}$} \\
\cline { 2 - 7 } Populations & SF & SS & FF & SF & SS & FF \\
\hline Wase Ataria & 3 & 4 & 0 & 5 & 2 & 0 \\
Pa Shi Tien & 1 & 6 & 1 & 1 & 0 & 7 \\
Tainung & 0 & 4 & 3 & 1 & 0 & 6 \\
Main Crop Benares & 4 & 3 & 1 & 3 & 0 & 5 \\
PI - 163485 & 3 & 4 & 0 & 5 & 2 & 0 \\
PI - 183214 & 1 & 0 & 1 & 2 & 0 & 0 \\
Kangaroo & 2 & 1 & 0 & 3 & 0 & 0 \\
Jaragua & 2 & 5 & 0 & 0 & 6 & 1 \\
Piracicaba Precoce & 3 & 5 & 0 & 4 & 2 & 2 \\
Piracicaba Precoce n. 1 & 8 & 0 & 0 & 8 & 0 & 0 \\
Piracicaba Precoce 439 & 1 & 6 & 1 & 6 & 2 & 0 \\
Teresópolis Gigante & 5 & 3 & 0 & 4 & 0 & 4 \\
\hline Total & 33 & 41 & 7 & 42 & 14 & 25 \\
\hline
\end{tabular}

$\mathrm{SF}=$ heterozygous plants for alleles $\mathrm{S}$ and $\mathrm{F}$.

$\mathrm{SS}=$ homozygous plants for allele $\mathrm{S}$.

$\mathrm{FF}=$ homozygous plants for allele $\mathrm{F}$.

$\mathrm{B} 1=$ locus segregation in APS-5.

formed by (i) the overlapping of two homodimers, formed by the products of alleles $\mathrm{A}_{1}{ }^{1}$ and $\mathrm{B}_{1}{ }^{1}$ (band e), (ii) interlocus heterodimers resulting from the combination of chains coded by alleles $\mathrm{B}_{1}{ }^{1}$ and $\mathrm{B}_{2}{ }^{2}$ (band d), and (iii) by a homodimer coded on locus $\mathrm{B}_{2}$ (band c). Pattern 2 would be formed by (i) a homodimer formed from the product of allele $\mathrm{A}_{1}{ }^{1}$ (band e), (ii) a homodimer formed from products coded by allele $\mathrm{B}_{2}$ (band c), (iii) an interlocus heterodimer formed from products coded by alleles $\mathrm{B}_{2}{ }^{2}$ and $\mathrm{B}_{1}{ }^{3}$ (band b), and (iv) a homodimer formed from products coded by allele $\mathrm{B}_{1}{ }^{3}$ (band a). Pattern 3 would be formed by the overlapping of two homodimers, formed by (i) products of alleles $\mathrm{A}_{1}{ }^{1}$ and $\mathrm{B}_{1}{ }^{1}$ (band e), (ii) interlocus heterodimers resulting from the combination of chains coded by alleles $\mathrm{B}_{1}{ }^{1}$ and $\mathrm{B}_{2}{ }^{2}$ (band d), (iii) the overlapping of a homodimer coded on locus $\mathrm{B}_{2}$ and an intralocus heterodimer formed by chains coded by alleles $\mathrm{B}_{1}{ }^{1}$ and $\mathrm{B}_{1}{ }^{3}$ (band c), (iv) a heterodimer formed from chains coded by allele $\mathrm{B}_{2}{ }^{2} \mathrm{~B}_{1}{ }^{3}$ (band b), and (v) a homodimer formed by the product of allele $\mathrm{B}_{1}{ }^{3}$ (band a). Thus, the isoenzymes observed in the APS-5 zone were coded in loci $A_{1}, B_{1}$, and $B_{2}$, and some of them were interlocus heterodimers. $\mathrm{B}_{1}$ was the only locus segregating in this zone. The similar electrophoretic mobility observed among the isozymes coded by the analyzed loci and the occurrence of interlocus heterodimers suggested gene duplication. Gene duplications have also been reported in other plant species (Stuber and Goodman, 1980; Massey and Hamrick, 1998).

Different frequencies were found for each allele of the two loci in the 12 analyzed populations (Table III). The frequencies of each phenotype in zones APS-1 and APS-3 were very similar, suggesting that APS-3 is most probably formed by interlocus heterodimers, as suggested previously by Arus and Shields (1983). In APS-1, the frequencies detected for phenotypes SF and SS were similar and much higher than the frequency of phenotype FF. In $\mathrm{B}_{1}$, the frequencies of phenotypes SS and FF were a little lower than that of SF, and more similar to each other than to APS-1. The frequencies of each phenotype varied in the population, that of SS generally being higher than those of SF and FF. The polymorphism within and among populations was generally very low, since only up to two alleles were found at the two loci analyzed. The populations differed from each other in the frequencies of these alleles.

The proportion of crosses using all analyzed lines resulting in hybrids that may be identified using loci APS-1 and $\mathrm{B}_{1}$ was calculated based on the total frequency of each phenotype (SS, FF, FS) (Table IV). The most useful locus was $\mathrm{B}_{1}$, by which $14.3 \%$ of the possible hybrids between any pair of the analyzed lines could be detected based on their band patterns, whereas APS-1 would allow the detection of no more than $8.8 \%$ of hybrids. If the crosses were done using the lines with genotypes FF or SS of each population (Table V), the proportion of crosses resulting in hybrids that might be identified using APS- 1 and $\mathrm{B}_{1}$ would be

Table IV - Frequencies of possible crosses based on the phenotypic frequencies found at loci APS-1 and $\mathrm{B}_{1}$ (Table III).

\begin{tabular}{llc}
\hline & \multicolumn{1}{c}{ APS-1 } & \multicolumn{1}{c}{$\mathrm{B}_{1}$} \\
\cline { 2 - 3 } Crossings & \multicolumn{1}{c}{ Frequencies } & \multicolumn{1}{c}{ Frequencies } \\
\hline SS $\times$ SS - $\mathrm{p}^{2}$ & $0.506 \times 0.506=0.256$ & $0.173 \times 0.173=0.029$ \\
SS $\times$ FF - 2pq & $2 \times 0.506 \times 0.086=0.088$ & $2 \times 0.173 \times 0.309=0.143$ \\
SS x SF - 2pr & $2 \times 0.506 \times 0.407=0.82$ & $2 \times 0.173 \times 0.516=0.268$ \\
FF x FF - q & $0.086 \times 0.086=0.007$ & $0.309 \times 0.309=0.100$ \\
FF x SF - 2qr & $2 \times 0.086 \times 0.407=0.070$ & $2 \times 0.309 \times 0.516=0.319$ \\
HH x HH - $\mathrm{r}^{2}$ & $0.407 \times 0.407=0.1656$ & $0.516 \times 0.516=0.266$ \\
\hline
\end{tabular}

$\mathrm{S}$ - slower migration allele.

F- faster migration allele.

$\mathrm{p}$ - frequency of homozygous plants for allele $\mathrm{S}$.

q - frequency of heterozygous plants for alleles S and F.

$\mathrm{r}$ - frequency of homozygous plants for allele F. 
Table $\mathbf{V}$ - Number of homozygous plants for the two loci, after exclusion of heterozygous plants. One of each kind of homozygous plants (SS or FF) were chosen from each population.

\begin{tabular}{lcccccc}
\hline & \multicolumn{3}{c}{ APS - } & & $\mathrm{B}_{1}$ \\
\cline { 2 - 7 } Populations & SF & SS & FF & SF & SS & FF \\
\hline Wase Ataria & 0 & 1 & 0 & 0 & 1 & 0 \\
Pa Shi Tien & 0 & 1 & 1 & 0 & 0 & 1 \\
Tainung & 0 & 1 & 1 & 0 & 0 & 1 \\
Main Crop Benares & 1 & 1 & 1 & 0 & 0 & 1 \\
PI - 163485 & 1 & 1 & 0 & 0 & 1 & 0 \\
PI - 183214 & 0 & 0 & 1 & 0 & 0 & 0 \\
Kangaroo & 0 & 1 & 0 & 0 & 0 & 0 \\
Jaragua & 0 & 1 & 0 & 0 & 1 & 1 \\
Piracicaba Precoce & 0 & 1 & 0 & 0 & 1 & 1 \\
Piracicaba Precoce n. 1 & 0 & 0 & 0 & 0 & 0 & 0 \\
Piracicaba Precoce 439 & 0 & 1 & 1 & 0 & 1 & 0 \\
Teresópolis Gigante & 0 & 1 & 0 & 0 & 0 & 1 \\
\hline Total & 0 & 10 & 4 & 0 & 11 & 6 \\
\hline
\end{tabular}

Table VI - Frequencies of possible crosses based on the phenotypic frequencies of loci APS- 1 and $\mathrm{B}_{1}$, when plants with pattern 3 and only one type of homozygous plant for each population are analyzed (Table IV).

\begin{tabular}{lll}
\hline & \multicolumn{1}{c}{ APS-1 } & \multicolumn{1}{c}{$\mathrm{B}_{1}$} \\
\hline Crossings & \multicolumn{1}{c}{ Frequencies } & \multicolumn{1}{c}{ Frequencies } \\
\hline SS $\times$ SS $-\mathrm{p}^{2}$ & $0.71 \times 0.71=0.5041$ & $0.45 \times 0.45=0.2025$ \\
SS $\times$ FF -2 pq & $2 \times 0.71 \times 0.29=0.4118$ & $2 \times 0.45 \times 0.55=0.495$ \\
FF $\times$ FF $-\mathrm{q}^{2}$ & $0.086 \times 0.086=0.007$ & $0.55 \times 0.55=0.3025$ \\
\hline
\end{tabular}

For abbreviations, see Table IV.

$41 \%$ and $50 \%$, respectively (Table VI). These results indicate that the acid phosphatase system can be very useful for hybrid identification in the analyzed lines, and that the genotyping of these lines could increase the efficiency of this marker.

\section{References}

Allen SL, Misch MS and Morrison BM (1963) Variations in the electrophoretically separated acid phosphatases of tetrahymena. J. Histochem. Cytochem 11:706-719.
Arús P and Shields CR (1983) Cole crops (Brassica oleracea L.) Isozymes in Plant Genetics and Breeding, Part B. Elsevier Publishers, Amsterdam.

Arus P, Shields CR and Orton TJ (1985) Application of isozyme electrophoresis for purity testing and cultivar identification of $F_{1}$ hybrids of Brassica oleracea. Euphytica 34:651-657.

Cardy BJ and Kannenberg LW (1982) Allozymic variability among maize inbred lines and hybrids: applications for cultivar identification. Crop Sci. 22:1016-1020.

Grossi C, Raymond O and Jay M (1997) Isozyme polymorphism of Rosa spa and cultivar identification. Euphytica 98:11-19.

Haruta T (1962) Studies on the Genetic of Self and Cross-incompatibility in Cruciferous Vegetable. Northurp King, Minneapolis.

Heidrich-Sobrinho E (1982) Isoenzimas como marcadores genéticos na identificação de novas linhagens de milho. Pesq. Agropec. Bras. 149:936-943.

Ikuta H (1979) Hibridos de couve-flor Piracicaba Precoce X Gigante de Teresópolis. Relat. Cient. Esc. Sup Agric. "Luiz de Queiroz", 8:76-77.

Ikuta H and Paterniani E (1979) Produtividade de sementes de linhagens homozigóticas autoincompatíveis do cultivar de couve-flor Piracicaba Precoce n. 1. Relat. Cient. Esc. Sup Agric. “Luiz de Queiroz”, 13:138-148.

Kephart SR (1990) Starch gel electrophoresis of plant isozymes: a comparative analysis of techniques. Am. J. Bot. 77:693-712.

Massey LK and Hamrick JL (1998) Genetic diversity and population structure of Yucca filamentosa (Agavaceae). Am. J. Bot. 85:340-345.

Nijenhius B (1971) Estimation of the proportion of inbred seed in Brussels sprout hybrid seeds by acid phosphatase isoenzyme analysis. Euphytica 20:498-507.

Stuber CW and Goodman MM (1980) Genetics of IDH isozymes in corn. Maize Genet. Coop. Newsletter 54:100.

Thompson KF (1957) Self-incompatibility in narrow stem kale $B$. oleracea var. aceplala. I. Demonstration of a saprophyte system. J. Genet. 55:45-60.

Wills AB, Fyfe SK and Wiseman EM (1979) Testing $F_{1}$ hybrids of Brassica oleracea for sibs by seed isozyme analysis. Ann. Appl. Biol. 91:263-270.

Wills AB and Wiseman EM (1980) Acid phosphate isoenzymes of Brassica oleracea seedlings and their application to sib testing in $\mathrm{F}_{1}$ hybrids. Ann. Appl. Biol. 94:137-142.

Woods S and Thurman DA (1976) The use of seed acid phosphatase in the determination of the purity in $\mathrm{F}_{1}$ hybrids. Euphytica 25:702-712. 